\title{
OriginaL
}

\section{Study on the mechanism causing elevation of serum CA19-9 levels in diabetic patients}

\author{
Jun Murai ${ }^{1)}$, Sumiko Soga ${ }^{1)}$, Hiroshi Saito ${ }^{1)}$, Michio Otsuki ${ }^{2)}$, Takatoshi Kitada ${ }^{3)}$, Yoshifumi Saisho ${ }^{4)}$, \\ Hideji Nakamura $^{5)}$, Soji Kasayama ${ }^{6)}$ and Masafumi Koga ${ }^{3)}$ \\ ${ }^{1)}$ Department of Internal Medicine, Kinki Central Hospital, Itami 664-8533, Japan \\ ${ }^{2)}$ Department of Metabolic Medicine, Osaka University Graduate School of Medicine, Osaka 565-0871, Japan \\ ${ }^{3)}$ Department of Internal Medicine, Kawanishi City Hospital, Kawanishi 666-0195, Japan \\ ${ }^{4)}$ Department of Internal Medicine, Keio University School of Medicine, Tokyo 160-8582, Japan \\ ${ }^{5)}$ Department of Gastroenterology, Nissay Hospital, Osaka 550-0012, Japan \\ ${ }^{6)}$ Department of Medicine, Nissay Hospital, Osaka 550-0012, Japan
}

\begin{abstract}
Serum CA19-9 levels are often elevated in diabetic patients. To elucidate this mechanism, we investigated the metabolism of CA19-9 in diabetic patients without obvious cancer. Study 1 included 119 patients in whom HbAlc, glycated albumin (GA) and CA19-9 were measured at the time of hospital admission. Study 2 examined 6 patients with markedly elevated CA19-9 levels ( $\geq 100 \mathrm{U} / \mathrm{mL}$ ). Their half-lives for HbA1c, GA, and serum CA19-9 were calculated using the data before and after diabetes treatment. Three diabetic patients with pancreatic cancer were also examined as controls. In Study 1, serum CA19-9 (logarithmically transformed value) was significantly correlated with fasting plasma glucose (FPG), HbAlc and GA. On multivariate analysis, GA and FPG, but not HbAlc, were significant explanatory variables for serum CA19-9. In Study 2, serum CA19-9 decreased together with HbA1c and GA after diabetes treatment. The calculated half-lives for HbAlc, GA, and serum CA19-9 were 33.8 days, 16.1 days, and 10.9 days, respectively. The half-life of serum CA19-9 was longer in the study patients than that reported in patients with malignant tumors. By contrast, in the diabetic patients with pancreatic cancer serum CA19-9 showed a marginal decrease after diabetes treatment. Taken all together, prolonged half-life of serum CA19-9 may contribute to the increase in serum CA19-9 levels in diabetic patients without obvious cancer.
\end{abstract}

Key words: CA19-9, Diabetes, HbA1c, Glycated albumin

CA19-9 is a tumor associated antigen recognized by the NS19-9 monoclonal antibody, which was produced using the SW1116 human colorectal carcinoma cell line [1]. Serum CA19-9 is elevated in patients with pancreatic cancers, cancers of the upper gastrointestinal tract, ovarian cancer, hepatocellular cancer and colorectal cancer, and is used clinically as a tumor marker [2]. Serum CA19-9 is also elevated in benign diseases such as cholecystitis [3] and pulmonary sequestration [4-6]. In diabetic patients, serum CA19-9 is also known to be elevated [7-10]. A positive correlation between

Submitted Oct. 10, 2012; Accepted Mar. 11, 2013 as EJ12-0364 Released online in J-STAGE as advance publication Apr. 3, 2013

Correspondence to: Masafumi Koga, M.D., Ph.D., Department of Internal Medicine, Kawanishi City Hospital, 5-21-1 HigashiUneno, Kawanishi 666-0915, Japan.

E-mail: m-koga@kawanishi-city-hospital.com serum CA19-9 and HbA1c [7, 11-13] and a decrease in serum CA19-9 with diabetes treatment $[8,12]$ have been reported, thus suggesting a relationship between serum CA19-9 and glycemic control state. However, the mechanism of elevated serum CA19-9 in diabetic patients is unclear.

In diabetic patients, as compared to non-diabetes, glycation of various proteins is known to be increased, and some of these proteins are thought to be involved in the onset and progression of chronic diabetic complications [13]. Among the glycated proteins, HbAlc is widely used clinically as an indicator for chronic control of plasma glucose levels $[14,15]$. Glycated albumin (GA) is also used as a glycemic control indicator [16]. Because the half-life of serum albumin is shorter than that of erythrocytes, GA reflects glucose levels over a shorter period (about 2 weeks) than HbAlc. 
Therefore, GA is more useful than HbAlc as a glycemic control marker for acute changes in glycemic control state [17].

In this study, as a mechanism of elevated serum CA19-9 in diabetic patients, we hypothesized that the half-life of serum CA19-9 was prolonged. Therefore, we investigated the relationship between serum CA19-9, fasting plasma glucose (FPG), and glycemic control indicators in diabetic patients. In addition, in diabetic patients with high serum CA19-9 levels, we examined the changes in serum CA19-9 before and after diabetes treatment. We calculated the half-life of serum CA19-9 and compared that with those of HbA1c and GA. Furthermore, we also examined the effect of diabetes treatment on serum CA19-9 in diabetic patients with pancreatic cancer.

\section{Methods}

\section{Study patients}

Study 1: This study included 119 diabetic patients who were admitted to Kinki Central Hospital for the diabetes treatment between April 2010 and March 2011; and in whom $\mathrm{HbA1c}$, GA and serum CA19-9 were measured at the time of hospital admission (Table 1). Patients with liver disease, kidney disease, anemia, or malignant diseases were excluded. In addition, in patients with high CA19-9 levels ( $>37 \mathrm{U} / \mathrm{mL})$, an abdominal ultrasound examination and/or contrast enhanced computed tomography (CT) scan was performed to rule out pancreatic cancer.

Study 2: Among the 119 patients in study 1, this study included 6 patients with markedly increased CA19-9 levels ( $\geq 100 \mathrm{U} / \mathrm{mL})$ at the time of admission, and whose subsequent clinical course was observed. Since all of these patients had poor glycemic control state, intensive insulin therapy was performed after admission.
After 2 weeks of hospitalization, $\mathrm{HbAlc}$, GA and serum CA19-9 were again measured, and the values were compared to those before diabetes therapy. Self-monitering of blood glucose was performed 4 times daily (before each meal and at bedtime) and the daily mean blood glucose (MBG) was calculated. In addition, MBG at admission was estimated form HbAlc using the following formula from Rohlfing et al. [18].

$$
\text { Estimated } \mathrm{MBG}=(\mathrm{HbA1} \mathrm{c}-2.17) \times 35.6 \cdots \cdots \text { Equation } 1
$$

Through a retrospective study we examined 3 diabetic patients with pancreatic cancer (all male, $71.7 \pm$ 11.7 years old) as controls whose serum CA19-9 were elevated $(204 \pm 104 \mathrm{U} / \mathrm{mL})$. Since their glycemic control state were poor $(\mathrm{HbAlc} ; 9.1 \pm 1.6 \%)$, insulin treatment was started. Before and after the treament, HbA1c and serum CA19-9 were measured. After glycemic control state was improved, operation (resection of pancreatic cancer) were perfomed. After the operation, serum CA19-9 in all patients decreased below the refernce value $(\leq 37 \mathrm{U} / \mathrm{mL})$.

This study was conducted after approval by the Ethics Committee at Kinki Central Hospital and after obtaining signed informed consent from the patients who participated.

\section{Calculation of half life}

We previously reported that the half-life of GA can be calculated using Equation 1, as shown below [19].

The half-life of GA=

$-0.3 \times t / \log \left(\mathrm{GA}_{t}-\mathrm{GA}_{\infty}\right) /\left(\mathrm{GA}_{o}-\mathrm{GA}_{\infty}\right) \cdots \cdots$ Equation 2

$t$ : number of days after the start of treatment; $\mathrm{GA}_{o}$ : GA before treatment; $\mathrm{GA}_{t}$ : GA after $t$ days of treatment; and $\mathrm{GA}_{\infty}$ : target-to-treat GA level. The $\mathrm{GA}_{\infty}$ is $15.0 \%$.

Table 1 Clinical characteristics of the study patients

\begin{tabular}{lcc}
\hline & Study 1 & Study 2 \\
\hline$n$ & 119 & 6 \\
male/female & $68 / 59$ & $4 / 2$ \\
Type 1 diabetes/type 2 diabetes & $6 / 113$ & $1 / 5$ \\
Age (years) & $62.3 \pm 13.2$ & $57.8 \pm 19.1$ \\
Body mass index $\left(\mathrm{kg} / \mathrm{m}^{2}\right)$ & $23.6 \pm 3.9$ & $22.5 \pm 4.5$ \\
Fasting plasma glucose $(\mathrm{mg} / \mathrm{dL})$ & $167 \pm 56$ & $183 \pm 32$ \\
HbA1c $(\%)$ & $10.6 \pm 1.9$ & $12.7 \pm 2.2$ \\
GA $(\%)$ & $31.9 \pm 9.1$ & $42.1 \pm 15.0$ \\
Serum CA19-9 $(\mathrm{U} / \mathrm{mL})$ & $34.9 \pm 45.2$ & $113 \pm 68$ \\
\hline
\end{tabular}


In study 2, the half-lives of GA, HbA1c and CA19-9 were calculated, based on the above equation, using the equations below.

$$
\begin{aligned}
& \text { GA half-life }= \\
& -0.3 \times 14 / \log \left(\mathrm{GA}_{14 d}-15.0\right) /\left(\mathrm{GA}_{0}-15.0\right) \ldots . . \text { Equation } 3 \\
& \text { HbA1c half-life }= \\
& -0.3 \times 14 / \log \left(\mathrm{HbAlc}_{14 d}-5.4\right) /\left(\mathrm{HbAlc}_{0}-5.4\right) \cdots \text { Equation } 4 \\
& \text { CA19-9 half-life }= \\
& -0.3 \times 14 / \log \left(\mathrm{CA} 19-9_{14 d}\right) /\left(\mathrm{CA} 19_{-9}\right) \cdots . . \text { Equation } 5
\end{aligned}
$$

$\mathrm{G}_{0}, \mathrm{~A} 1 \mathrm{c}_{0}, \mathrm{CA} 19-9_{0}: \mathrm{GA}, \mathrm{HbA1c}$, and CA19-9 before

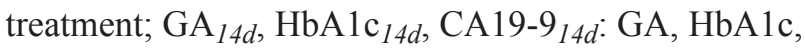
and CA19-9 after 14 days of treatment. The target-totreat $\mathrm{HbA} 1 \mathrm{c}$ level was 5.4\%.

Although Yoshimasu et al. [20] calculated the halflife of the first compartment and the second compartment of disappearance curves of serum CA19-9 from the data before and after surgery in patients with cancer. Equation 5 which was used to calculate the halflife of CA19-9 in this study is a formula for calucalating the half-life of the first compartment [20].

\section{Laboratory analyses}

Plasma glucose was determined using the hexokinase, glucose-6-phosphate dehydrogenase method. HbA1c was measured with ADAMS-A1c HA-8180 (Arkray Inc., Kyoto, Japan) by high performance liquid chromatography [21]. The value for HbAlc (\%) was estimated as a National Glycohemoglobin Standardization Program (NGSP) equivalent value (\%) calculated by the formula HbAlc (\%) = HbAlc (Japan Diabetes Society: JDS) (\%) $+0.4 \%$, based on the relational expression of HbA1c (JDS) (\%) measured by the previous Japanese standard substance and measurement methods and HbA1c (NGSP) [21]. GA was determined with a Hitachi 7600 autoanalyzer (Hitachi Instruments Service Co., Tokyo, Japan) by the enzymatic method using albumin-specific proteinase, ketoamine oxidase, and albumin assay reagent (Lucica GA-L; Asahi Kasei Pharma Co., Tokyo, Japan) [22]. Serum CA19-9 was measured by the chemiluminescent immunoassay (CLIA) method.

\section{Statistical analyses}

All data are shown as means \pm SD. To correct for skewed distributions, serum CA19-9 concentrations were logarithmically transformed. For statistical analyses, Wilcoxon rank sum test or Mann-Whitney U test were used to compare the two groups as appropriate. To analyze the effects of confounding variables on serum CA19-9, univariate regression analysis as well as stepwise multivariate regression analysis was performed with the StatView computer program (Version 5.0 for Windows, Abacus Concepts, Berkeley, CA). In the stepwise multiple regression analysis, the F-value for the inclusion of variables was set at 4.0. $P$ values of $<0.05$ were considered to be statistically significant.

\section{Results}

\section{Study 1}

The mean $\mathrm{HbAlc}$ and GA before treatment was $10.6 \pm 1.9 \%$ and $31.9 \pm 9.1 \%$, respectively, indicating poor glycemic control state (Table 1). Serum CA19-9 exceeded the reference value $(\leq 37 \mathrm{U} / \mathrm{mL})$ in 33 of 119 patients (27.7\%). Serum CA19-9 (logarithmically transformed) was significantly correlated with FPG, HbA1c and GA (Fig. 1). The correlation coefficients were larger in order of GA, FPG and HbAlc. Multivariate analysis for serum CA19-9 (logarithmically transformed) was performed with age, sex, body mass index, FPG, HbA1c and GA, as explanatory variables. GA $(\beta=0.326, \mathrm{~F}=14.1, p=0.005)$ and $\mathrm{FPG}(\beta=0.253, \mathrm{~F}=8.5$, $p=0.010)$ were significantly positive explanatory variables for serum CA19-9. On the other hand, HbA1c was not a significant explanatory variable.

\section{Study 2}

$\mathrm{HbAlc}$ and GA in the patients in study 2 before treatment were both markedly elevated, indicating poor glycemic control state (Table 1). Intensive insulin therapy was started immediately after admission and rapid decrease in blood glucose levels was obeserved. MBG, which was estimated from HbA1c (12.7\%) at admission, was $384 \pm 78 \mathrm{mg} / \mathrm{dL}$ and that on day 1 , on day 8 and on day 14 after admission was $247 \pm 62 \mathrm{mg} / \mathrm{dL}$, $146 \pm 24 \mathrm{mg} / \mathrm{dL}, 126 \pm 15 \mathrm{mg} / \mathrm{dL}$, respectively.

Fig. 2 shows the changes in $\mathrm{HbA1c}$, GA and serum CA19-9 before and 2 weeks after diabetes treatment. Along with the diabetes treatment, $\mathrm{HbAlc}$ decreased significantly from $12.7 \pm 2.2 \%$ to $11.2 \pm 1.4 \%(p<0.05)$, and GA decreased significantly from $42.1 \pm 15.0 \%$ to $29.9 \pm 10.4 \%(p<0.05)$. Serum CA19-9 decreased significantly from $113 \pm 68 \mathrm{U} / \mathrm{mL}$ to $34.2 \pm 10.6 \mathrm{U} / \mathrm{mL}$ 

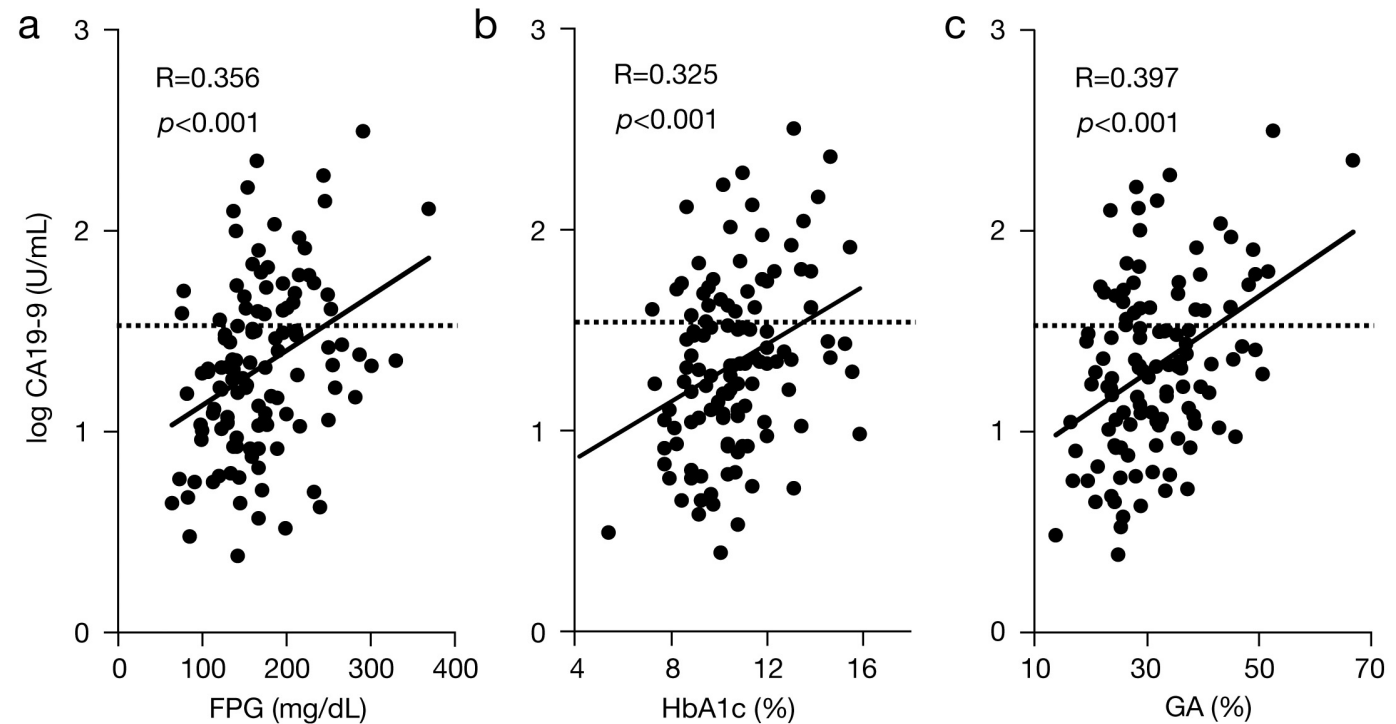

Fig. 1 Correlations of serum CA19-9 (logarithmically transformed) with FPG (a), HbA1c (b) and GA (c)

The dotted lines represent the normal reference values of serum CA19-9 $(37 \mathrm{U} / \mathrm{mL})$.

$(p<0.05)$. From these data, the calculated half-lives for HbA1c, GA, and serum CA19-9 were $33.8 \pm 12.8$ days, $16.1 \pm 3.6$ days, and $10.9 \pm 4.1$ days, respectively (Fig. 2). The half-lives for GA and serum CA19-9 were significantly shorter than that for HbA1c $(p<0.05)$.

In 3 diabetic patients with pancreatic cancer $\mathrm{HbA} 1 \mathrm{c}$ decreased from $9.1 \pm 1.5 \%$ to $7.4 \pm 0.6 \%$ after insulin treatment for $40 \pm 13$ days. On the other hand, serum CA19-9 showed a marginal decrease from $204 \pm 104$ $\mathrm{U} / \mathrm{mL}$ to $169 \pm 90 \mathrm{U} / \mathrm{mL}(-15 \pm 19 \% ;-36 \% \sim+2 \%)$ (Fig. $3)$. The calculated half-lives for HbAlc and serum CA19-9 were $55.7 \pm 22.2$ days and more than 116 days, respectively. Whereas the half-life for $\mathrm{HbAlc}$ in the patients with pancreatic cancer was not different from that in the patients without obvious cancer, the half-life for CA19-9 in the patients with pancreatic cancer was significantly longer than that in the patients without obvious cancer $(p<0.05)$.

\section{Discussion}

In diabetic patients, a significant correlation between serum CA19-9 with FPG and HbA1c has already been reported [11-13]. We firstly found that serum CA19-9 was also significantly correlated with GA in this study. Importantly, with diabetes treatment, serum CA19-9 decreased along with both $\mathrm{HbAlc}$ and GA, which suggests the existence of a regulatory mechanism for serum CA19-9 via glycemic control state. On multivar- iate analysis, HbA1c was not a significant explanatory variable, whereas both GA and FPG were significant explanatory variables for serum CA19-9. When halflives were calculated based on the decrease in $\mathrm{HbAlc}$ and GA with diabetes treatment, these were $33.8 \pm 12.8$ days and $16.1 \pm 3.6$ days, respectively, which are similar to the values reported previously [24]. The half-life (of the first component of the disappearance curves) of serum CA19-9 was $10.9 \pm 4.1$ days. The reason that serum CA19-9 was significantly correlated with GA, but not with $\mathrm{HbAlc}$, is presumably due to the close half-life period of serum CA19-9 to that of GA.

CA19-9 is expressed in small amounts on the surface of normal epithelial cells, but with malignant transformation, large amounts of CA19-9 are produced at these sites, results in increased serum levels. In other words, in patients with malignant tumors, CA19-9 production is increased and serum CA19-9 levels increase. In patients with malignant tumors with elevated serum CA19-9 levels, Yoshimasu et al. [20] reported the halflife of the first compartment and the second compartment of the disappearance curves of serum CA19-9 was $0.5 \pm 0.1$ days and $4.3 \pm 1.5$ days, respectively and Rapellino et al. [25] reported the half-life (of the first compartment) was 1.1 days, calculated based on the decay curves when tumors are surgically resected. The half-life of CA19-9 in the diabetic patients in this study was extremely prolonged compared with that in patients with cancer. However, because improvement 

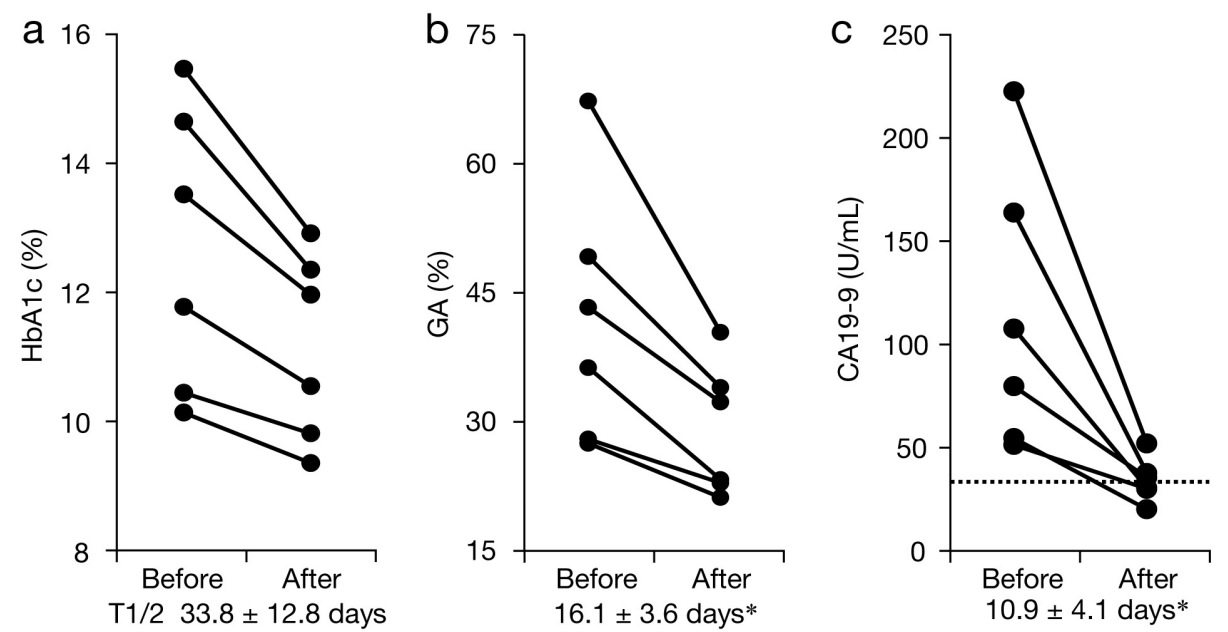

Fig. 2 Courses of HbA1c, GA and serum CA19-9 before and after 2 weeks of diabetes treatment in the diabetic patients without obvious cancer

Using the HbAlc (a), GA (b) and serum CA19-9 (c) values before and after 2 weeks of diabetes treatment, their half-lives were calculated as described in the Methods section. The dotted line represents the normal reference values of serum CA19-9 (37 $\mathrm{U} / \mathrm{mL}) .{ }^{*}, p<0.05 v s . \mathrm{HbA} 1 \mathrm{c}$

of glycemic control is not so rapid, half-life of CA19-9 in diabetic patients might be apparently prolonged. In this study, since the patients with poor glycemic control were treated with intensive insulin therapy, MBG decreased from $384 \pm 78 \mathrm{mg} / \mathrm{dL}$ to $247 \pm 62 \mathrm{mg} / \mathrm{dL}$ for 1 day. If target levels of MBG were set at $100 \mathrm{mg} / \mathrm{dL}$, the half-life of MBG was approximately 1 day. As a result, the true half-life of CA19-9 was assumed to be 9-10 days. The adjusted half-life of CA19-9 in diabetic patients was also obviously prolonged compared with it in patients with cancer.

The mechanism of elevated serum CA19-9 in diabetic patients has remained unclear. Aoki et al. [26] reported that the CA19-9 antigen was predominantly a $\geq 1000 \mathrm{kDa}$ molecular weight fraction in patients with pancreatic cancer, whereas there was predominantly a lower $\leq 700 \mathrm{kDa}$ molecular weight fraction in diabetic patients. Regarding this difference in molecular weights, they proposed that there may be increased sialylation due to hyperglycemia. Moreover, they proposed that synthesis of CA19-9 may be increased via an increase in sialylation. In our study, the half-life of CA19-9 was about 11 days calculated from the data in diabetic patients with elevated serum CA19-9 levels. This is clearly longer as compared to about 1 day in patients with malignant tumors. Based on these results, we firstly demonstrated a longer half-life of serum CA19-9 as a factor for elevated serum CA19-9 levels in diabetic patients. Although the detailed mech-
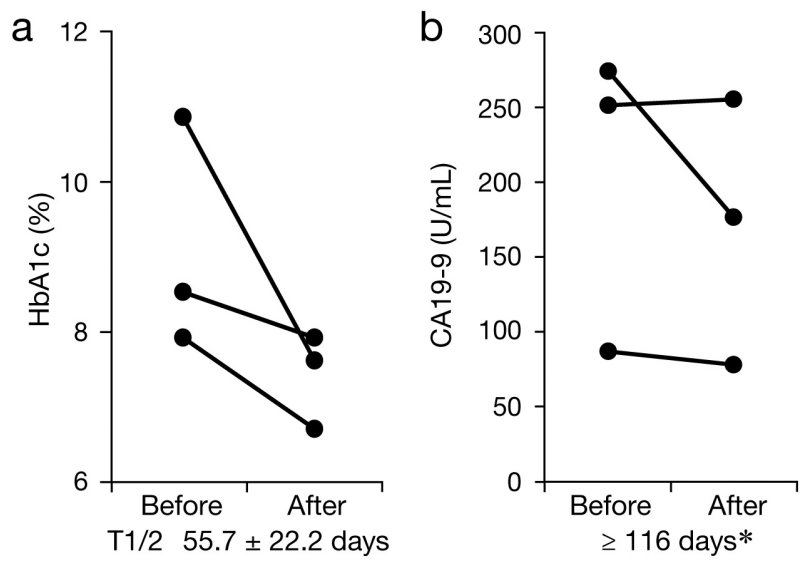

Fig. 3 Courses of HbA1c and serum CA19-9 before and after diabetes treatment in the diabetic patients with pancreatic cancer

Using the HbAlc (a) and serum CA19-9 (b) values before and after diabetes treatment, their half-lives were calculated as described in the Methods section. ${ }^{*}, p<0.05$ $v s$. the diabetic patients without obvious cancer (Fig. 2c)

anism is unclear, its catabolism may be decreased in diabetic patients probably because of increased glycation of CA19-9 and/or protein(s) involved in the catabolism of CA19-9.

Serum CA19-9 levels are also elevated in pulmonary sequestration [4-6]. Because of intense staining of affected bronchial glands and bronchiolar epithelium by immunostaining, increased production of CA19-9 at these sites has been proposed [27]. On the 
other hand, serum CA19-9 normalizes when lesions are resected. The half-life, calculated from the rate of decrease in serum CA19-9 at that time, was about 7 days; which is also longer as compared to that (about 1 days) in patients with malignant tumors [28]. An interesting proposal based on these results is that in patients with pulmonary sequestration the synthesis of CA19-9 is increased and its catabolism is also decreased.

CA19-9 is a sialylated Lewis A (sLe $)^{\mathrm{a}}$ structure in which sialic acid is attached to the Lewis A carbohydrate chain $\left(\mathrm{Le}^{\mathrm{a}}\right)$ of a Lewis blood group, and a fucosyl is attached to the CA19-9 precursor (sialyl Le ${ }^{\mathrm{C}}$ ). The reaction requires $\alpha 1-4$ fucosyl transferase, but this enzyme is deleted in the Lewis blood group (a-b-); thus, sLe ${ }^{\text {a }}$ (CA19-9) cannot be produced and serum CA19-9 is low. Therefore, serum CA19-9 levels differ depending on the Lewis blood group phenotype [29]. The distribution of the Lewis blood group phenotype does not differ between diabetic patients and controls, so this can be excluded as a cause of elevated CA19-9 levels in diabetic patients [13]. In diabetic patients, serum CA19-9 levels are highest in order of Lewis blood groups Le (a+b-), Le (a-b+) and Le (a-b-) [13]. Among the present study patients, some had normal serum CA19-9, despite markedly elevated HbA1c and GA. In our study, Lewis antigen was not evaluated, but the Lewis blood type in these patients may have been Le (a-b-).

In diabetic patients, glycemic control state can also worsen if pancreatic cancer develops [30]. Therefore, in diabetic patients in whom glycemic control worsens, the possibility of pancreatic cancer must be kept in mind. If serum CA19-9 levels are high in such patients, pancreatic cancer must be considered in the differential diagnosis, and imaging studies should be per- formed. Since the half-lives of CA19-9 in all patients were less than 2 weeks (5.0-12.6 days) in this study, serum CA19-9 decreased by more than 50\% through intensive insulin therapy for 2 weeks. On the other hand, serum CA19-9 in the patients with pancreatic cancer showed a marginal decrease after diabetes treatment. Their half-lives for CA19-9 were longer than those for HbA1c. Their serum CA19-9 did not decrease more than 50\% with insulin therapy for 5-6 weeks. Therefore, if serum CA19-9 decreases by more than $50 \%$ after intensive insulin therapy for 2 weeks, we could judge the high serum CA19-9 in diabetic patients is due to hyperglycemia. On the other hand, if serum CA19-9 does not decrease by more than 50\% after intensive insulin therapy for 2 weeks whereas GA is decreased dramatically, the presence of cancer might be suspected. In these cases, the examinations to find cancer are necessary. Using this strategy, it might be possible to omit unnecessary examination and reduce the burden of patients.

This study has several limitations. First, the study on diabetic patients with pancreatic cancer was a retrospective analysis. Second, the measurements of CA19-9 and HbAlc in these patients were performed on different time from those in diabetic patients without obvious cancer after diabetes treatment. Lastly, the number of patients in study 2 was small. Thus, a prospective study with a larger sample size will be necessary to confirm the findings in this study.

\section{Conflicts of Interest}

The authors declare no conflict of interest relevant to this manuscript.

\section{References}

1. Koprowski H, Steplewski Z, Mitchell K, Herlyn M, Herlyn D, et al. (1979) Colorectal carcinoma antigens detected by hybridoma antibodies. Somatic Cell Genet 5: $957-971$

2. Goonetilleke KS, Siriwardena AK (2007) Systematic review of carbohydrate antigen (CA19-9) as a biochemical marker in the diagnosis of pancreatic cancer. Eur $J$ Surg Oncol 33: 266-270.

3. Murohisa T, Sugaya H, Tetsuka I, Suzuki T, Harada T (1992) A Case of common bile duct stone with cholangitis presenting an extraordinarily high serum CA19-9 value. Intern Med 31: 516-520.

4. Yagyu H, Adachi H, Furukawa K, Nakamura H, Sudoh A, et al. (2002) Intralobar pulmonary sequestration presenting increased serum CA19-9 and CA125. Intern Med 41: 875-878.

5. Fontana D, Della Beffa V, Fusca M, Loddo F (2007) Extralobar pulmonary sequestration showing high CA 19-19 levels. Minerva Chir 62: 39-42

6. Ambiru S, Nakamura S, Fukasawa M, Mishima O, Kuwahara T, et al. (2009) Intralobar pulmonary sequestration associated with marked elevation of serum car- 
bohydrate antigen 19-9. Ann Thorac Surg 88: 20102011.

7. Shimojo N, Naka K, Nakajima C, Ishizaki T, Okuda K, et al. (1990) The effect of non-insulin-dependent diabetes on serum concentrations of tumor-associated carbohydrate antigens of CA19-9, CA-50, and sialyl SSEA-1 in association with the Lewis blood phenotype. Clin Chim Acta 190: 283-289.

8. Aoki N, Kagita A, Ohno Y, Imamura M, Saika T, et al. (1989) Elevation of CA19-9 levels in diabetic patients. Med Sci Res 17: 867-868.

9. Petit JM, Vaillant G, Olsson NO, Guignier F, Collignon S, et al. (1994) Elevated serum CA19-9 levels in poorly controlled diabetic patients. Relationship with Lewis blood group. Gastroenterol Clin Biol 18: 17-20.

10. Uygur-Bayramicli O, Dabak R, Orbay E, Dolapcioglu C, Sargin M, et al. (2007) Type 2 diabetes mellitus and CA 19-9 levels. World J Gastroenterol 13: 5357-5379.

11. Nakamura H, Katsumi T, Nagata S, Saito M, Konaka C, et al. (1997) A resected case of intralobar pulmonary sequestration with increased serum tumor markers, CA19-9, CA1525 and NCC-ST-439. Ann Jpn Resp Soc 35: 1425-1429 (In Japanese).

12. Benhamou PY, Vuillez JP, Halimi S, Meffre G, Bachelot I (1991) Influence of metabolic disturbances of diabetes mellitus on serum CA 19-9 tumor marker. Diabete Metab 17: 39-43.

13. Cohen MP (1988) Nonenzymatic glycation: a central mechanism in diabetic microvasculopathy? $J$ Diabet Complications 2: 214-217.

14. Koenig RJ, Peterson CM, Jones RL, Saudek C, Lehrman $\mathrm{M}$, et al. (1976) Correlation of glucose regulation and hemoglobin AIc in diabetes mellitus. N Engl J Med 295: 417-420.

15. Bunn HF, Gabbay KH, Gallop PM (1978) The glycosylation of hemoglobin: relevance to diabetes mellitus. Science 200: 21-27.

16. Koga M, Kasayama S (2010) Clinical usefulness of glycated albumin as an another glycemic control marker. Endocr J 57: 751-562.

17. Takahashi S, Uchino H, Shimizu T, Kanazawa A, Tamura Y, et al. (2007) Comparison of glycated albumin (GA) and glycated hemoglobin (HbAlc) in type 2 diabetic patients: usefulness of GA for evaluation of short-term changes in glycemic control. Endocr $J$ 54: 139-144.

18. Rohlfing CL, England JD, Wiedmeyer HM, Tennill A, Little RR, et al. (2002) Defining the relationship between plasma glucose and $\mathrm{HbA}_{1 \mathrm{c}}$. Diabetes Care 25 275-278.

19. Koga M, Murai J, Saito H, Kasayama S (2011) Prediction of near-future glycated hemoglobin levels using glycated albumin levels before and after treatment for diabetes. J Diabetes Invest 2: 304-309.

20. Yoshimasu T, Maebeya S, Suzuma T, Bessho T, Tanino H, et al. (1999) Disappearance curves for tumor markers after resection of intrathoracic malignancies. Int $J$ Biol Markers 14: 99-105.

21. Schnedl WJ, Lahousen T, Wallner SJ, Krause R, Lipp RW (2005) Silent hemoglobin variants and determination of HbAlc with the high-resolution program of the HPLC HA-8160 hemoglobin analyzer. Clin Biochem 38: $88-91$.

22. The Committee of Japan Diabetes Society on the Diagnostic Criteria of Diabetes mellitus. (2010) Report of the committee on the classification and diagnostic criteria of diabetes mellitus. J Diabetes Invest 1: 212228.

23. Kouzuma T, Usami T, Yamakoshi M, Takahashi M, Imamura S (2002) An enzymatic method for the measurement of glycated albumin in biological samples. Clin Chim Acta 324: 61-71.

24. Tahara Y, Shima K (1995) Kinetics of HbA1c, glycated albumin, and fructosamine and analysis of their weight functions against preceding plasma glucose level. Diabetes Care 18: 440-447.

25. Rapellino M, Piantino P, Pecchio F, Ruffini E, Cavallo A, et al. (1994) Disappearance curves of tumor markers after radical surgery. Int J Biol Markers 9: 33-37.

26. Aoki N, Ito K, Ohno Y (1994) Elevation of serum CA19-9 levels in diabetes mellitus is due to an increase of low molecular weight moieties. J Jpn Soc Cancer Ther 29: 62-72.

27. Shiota Y, Kitade M, Furuya K, Ueda N (1988) A case of intralobar pulmonary sequestration with high serum CA19-9 levels. Acta Med Okayama 42: 297-300.

28. Nakamura N, Aoji O, Yoshikawa T, Mori K, Kajiyama S, et al.(1986) Elevated serum CA19-9 levels in poorly controlled diabetic patients. Jpn J Med 25: 278-280.

29. Hansson GC, Zopf D (1985) Biosynthesis of the cancerassociated sialyl-Le ${ }^{a}$ antigen. J Biol Chem 260: 93889392.

30. Cui Y, Andersen DK (2011) Pancreatogenic diabetes: special considerations for management. Pancreatology 11: $279-294$. 